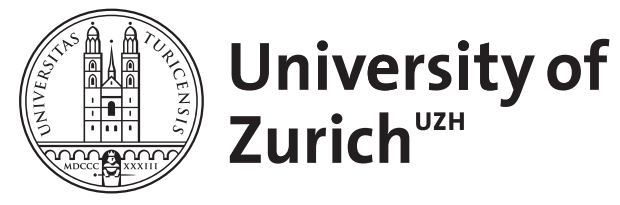

\title{
Expanding DBS indications: Reminder of the consequences of establishing a
} therapeutic practice

\author{
Christen, Markus ; Müller, Sabine
}

DOI: https://doi.org/10.1080/21507740.2013.782911

Posted at the Zurich Open Repository and Archive, University of Zurich ZORA URL: https://doi.org/10.5167/uzh-81527

Journal Article

Accepted Version

Originally published at:

Christen, Markus; Müller, Sabine (2013). Expanding DBS indications: Reminder of the consequences of establishing a therapeutic practice. AJOB Neuroscience, 4(2):57-58.

DOI: https://doi.org/10.1080/21507740.2013.782911 
Open peer commentary of: Ethical Considerations in Deep Brain Stimulation for the Treatment of Addiction and Overeating Associated with Obesity, by Jared Pisapia et al.

\section{Blinded manuscript}

\section{Expanding DBS indications: Remind the consequences of establishing a therapeutic practice}

Jared Pisapia and coauthors provide a sophisticated analysis of the ethical pitfalls of expanding Deep Brain Stimulation (DBS) as a therapeutic option for addiction and overeating associated with obesity. We agree with their expectation that DBS is a promising treatment for these conditions. However, the authors' assessment of ethical issues of this research field lacks the long-term perspective of turning (successful) clinical trials into routine clinical practice.

We propose to assess such long-term consequences along two dimensions: The first one is the patient-related dimension which involves, among others, information of patients, informed consent in normal treatment and research, shared decision-making, criteria for patient selection, the assessment of outcome parameters, the psychosocial impact of the treatment, and follow-up strategies. The second dimension is the infrastructure-related dimension which captures all aspects that are important for the development of a DBS infrastructure which can guarantee high-quality interventions. This includes issues like differences in technical and organizational procedures of centers, financing DBS interventions and research, long-term planning of center development, the information flow towards the public about chances and risks of DBS, and legislative issues of DBS (Abosch et al., 2012; Fins et al., 2012).

We recently have performed two surveys among DBS experts $(n=113)$ and DBS centers $(n=135)$ on the global practice of DBS (Christen et al., in preparation) that indeed indicate, as Pisapia and coauthors mention, that the indication spectrum of DBS is rapidly expanding. This trend includes even diseases for which many DBS experts think that the success probability of DBS is low (e.g. Alzheimer's disease). This trend is, according to many experts, driven also by commercial interests. Of the centers in our survey, $16.3 \%$ plan to implement DBS research on addiction and $12.6 \%$ on obesity within the next five years - i.e. it is indeed timely to start thinking on ethical consequences of this notably expansion.

Some of our findings outline additional ethical aspects that need to be considered and that go beyond mere research ethics that is the primary focus of Pisapia and colleagues. First, in the patientrelated dimension, the information and the attitudes of the gate keepers to DBS, namely those physicians who are the key players with respect to patient information and patient referral, have to be considered. This is important since the portions of patients and family members with realistic expectations significantly correlate with a positive evaluation of DBS, and doubts as well as unrealistic expectations correlated with a negative attitude towards the operation (Südmeyer et al., 2012). Furthermore, the communication of physicians with patients about medical interventions with a high degree of scientific uncertainty about their benefits and harms, is influenced both by individual differences in physicians' tolerance of uncertainty as well as physicians' beliefs about their patients' tolerance of uncertainty (Portnoy 2011). Therefore, these two aspects of uncertainty tolerance of the gate keepers are decisive for the quality of information and referral of patients. For Parkinsonian patients, we have found that the neurologists in private practice are the gate keepers to DBS. With respect to DBS in addiction and obesity, it has to be investigated who would and should be the gate keepers and how adequate patient information and patient referral can be guaranteed. We expect that the referral practice will differ because these two conditions have different gate keepers: Patients suffering from addiction usually have regular contacts with social workers who are traditionally critical with respect to biological disease models and biomedical interventions for changing behavior. But if they are treated by psychiatrists (particularly in university hospitals), they might find gate keepers who are interested in DBS research. In contrast, given the multiple causes of obesity, different medical specializations will become gate keepers for DBS. Furthermore, we expect that a few cases of successfully treated obese patients will cause a media hype which will raise 
Open peer commentary of: Ethical Considerations in Deep Brain Stimulation for the Treatment of Addiction and Overeating Associated with Obesity, by Jared Pisapia et al.

unrealistic expectations in people with quite different causes of obesity. This will lead to a patientdriven demand for DBS. In summary, we expect that physicians, who will become gate keepers for DBS for the treatment of addiction or obesity, will be confronted with demands for which they normally lack competence.

Second, we have found in our surveys that experts underestimate the frequency of some sequelae when compared with the literature. This does not necessarily indicate that the experts underestimate actual risks, as the expert opinions may reflect an improvement in practice that has not yet been included in reviews, which are usually based on outcome studies that reflect the stateof-the art of some years ago. However, it could also hint to a "habituation effect" for established DBS-indications, which is further corroborated by the findings that one third of the centers involve only the core team (neurology and neurosurgery) and maximal one additional discipline (e.g., psychiatry, neuropsychology) in routine interventions, and that more than half of the centers use devise programming times that are lower than recent guidelines suggest. Such habituation effects may be inevitable, as they may also be related to efforts to reduce the costs of the intervention. But therefore one should analyze whether such habituation effects may also happen for novel patient groups and to what extent this may endanger the quality of the intervention.

A third aspect refers to the infrastructure-related dimension and concerns the impact of novel DBS indications on the capacity of DBS centers. As Pisapia and colleagues point out, addiction and particularly obesity affect many people - raising the question, how many additional DBS patients had to be expected if DBS turned out to be effective in these conditions. Indeed, to estimate the future patient load for DBS centers is a difficult question even regarding only the established DBS conditions for several reasons: First the referral praxis of movement disorder specialists compared to other physicians differs significantly in identifying appropriate candidates for established as well as for novel indications (Katz, 2011). Second, the referring physicians underestimate the number of suitable patients (Oyama et al., 2012). Third, women are under-represented in the patients referred (Setiavan et al., 2006); this might change in future. A reasonable guess is that 10-20\% of PD patients qualify for DBS (Christen \& Müller, 2012) - but according to our research, countries like Canada, England, Italy and Japan may have insufficient capacities in order to deal already with the current patient load. As DBS is a high-tech intervention requiring considerable investment in material and manpower, an ethical evaluation of research on indications that have the potential to substantially increase the number of persons receiving DBS must take such issues into account.

Finally, as Pisapia and colleagues note, manipulating the reward center may have long-term consequences for the ability to enjoy life and to pursue goals, and for the social embedding of patients. As known from movement disorders, DBS can have paradox effects, namely psychosocial problems in spite of a good clinical outcome (overview: Müller \& Christen, 2011). Such problems may occur more frequently and in an aggravated manner when the reward system is targeted by DBS.

Taking all these points together, the ethical assessment of the expansion of DBS indications requires additionally to the analysis of research ethical issues an analysis of foreseeable consequences when potentially successful clinical trials will turn into routine practice.

\section{References}

Abosch, A., Timmermann, L., Bartley, S., Rietkerk, H.G., Whiting, D., Connolly, P.J., et al. 2013. An international survey of deep brain stimulation procedural steps. Stereotact Funct Neurosurg. 91(1): $1-11$. 
Open peer commentary of: Ethical Considerations in Deep Brain Stimulation for the Treatment of Addiction and Overeating Associated with Obesity, by Jared Pisapia et al.

Christen, M., Ineichen, C., Bittlinger, M., Bothe, H.-W., Müller, S. The practice of Deep Brain Stimulation - An international survey about clinical and ethical issues. In preparation for Movement Disorders.

Christen, M., Müller, S. 2012. Current status and future challenges of deep brain stimulation in Switzerland. Swiss Medical Weekly 142: w13570.

Fins, J.J., Dorfman, G.S., Pancrazio, J.J. 2012. Challenges to deep brain stimulation: a pragmatic response to ethical, fiscal, and regulatory concerns. Ann N Y Acad Sci. 1265:80-90.

Katz, M., Kilbane, C., Rosengard, J., Alterman, R.L., Tagliati, M. 2011. Referring patients for deep brain stimulation. An improving practice. Arch Neurol. 68(8): 1027-1032.

Müller, S., Christen, M. 2011. Deep Brain Stimulation in Parkinsonian patients - Ethical evaluation of stimulation-induced personality alterations. AJOB Neurosci. 2(1): 3-13.

Oyama, G., Rodriguez, R.L., Jones, J.D., Swartz, C., Merritt, S., Unger, R., et al. 2012. Selection of Deep Brain Stimulation candidates in private neurology practices: referral may be simpler than a computerized triage system. Neuromodulation 15: 246-250.

Portnoy, D.B., Han, P.K., Ferrer, R.A., Klein, W.M., Clauser, S.B. 2011. Physicians' attitudes about communicating and managing scientific uncertainty differ by perceived ambiguity aversion of their patients. Health Expect. doi: 10.1111/j.1369-7625.2011.00717.x.

Setiawan, M., Kraft, S., Doig, K., Hunka, K., Haffenden, A., Trew, M., et al. 2006. Referrals for movement disorder surgery: under-representation of females and reasons for refusal. Can J Neurol Sci. 2006; 33: 53-57.

Südmeyer, M., Volkmann, J., Wojtecki, L., Deuschl, G., Schnitzler, A., Möller B. 2012. Tiefe Hirnstimulation - Erwartungen und Bedenken. Bundesweite Fragebogenstudie mit ParkinsonPatienten und deren Angehörigen. Nervenarzt 83(4): 481-486. 